\title{
A TRADUÇÃO DAS EPÍSTOLAS BAUDELAIRIANAS: NOVAS PERSPECTIVAS DO MITO BAUDELAIRE, O "PRÍNCIPE DAS CARNIÇAS"
}

\begin{abstract}
Gilles Jean Abes*
Resumo: Este artigo pretende apresentar novas perspectivas sobre o poeta francês Charles Baudelaire decorrentes da tradução de algumas de suas cartas. Trata-se de debater os valores que tal tradução pode trazer à renovação da imagem do poeta de As flores do mal. Pois existe um mito Baudelaire, alimentado por ele mesmo, que camufla sua verdadeira personalidade ou, ao menos, simplifica a personagem. Nesse sentido, questiona-se neste trabalho a imagem de poeta maldito, revoltado com o segundo casamento da mãe e que não teria superado a fase edipiana. Eis o perfil que o principal tradutor de seus versos no Brasil, Ivan Junqueira, defende sob influência de Jean-Paul Sartre. Ora, a tradução/leitura das cartas lança um novo olhar sobre o poeta que possibilita certamente evitar uma leitura por demais mistificada/simplificada de sua personalidade e, talvez até mesmo de seus versos.

Palavras-chave: Tradução; cartas; Baudelaire; perspectivas.
\end{abstract}

Partindo-se da afirmação compartilhada por muitos teóricos da tradução de que "traduzir é a forma mais atenta de

\footnotetext{
* Doutorando em Estudos da Tradução na Pós-gradução em Estudos da Tradução (PGET) pela Universidade Federal de Santa Catarina.
} 
ler", ${ }^{1}$ este artigo procura analisar a correspondência de Charles Baudelaire a partir da leitura mais atenta que me foi imposta durante a tradução de suas cartas. Não se pretende apresentar as traduções das cartas baudelairianas em si, cuja tarefa está sendo realizada, mas investigar uma dúvida decorrente do ato tradutório, aquilo mesmo que revelam as cartas ao se embaterem à imagem difundida pelo principal tradutor do poeta das "flores doentias". De fato, há um choque entre os comentários de Ivan Junqueira a respeito de Baudelaire e as epístolas. Esse embate tem por resultado uma dúvida lacunar que clama por uma investigação mais pormenorizada, no intuito de questionar o mito que cerca o poeta. $\mathrm{O}$ que parece irromper de uma abordagem panorâmica desses escritos epistolares é a certeza de uma dúvida que se reveste da promessa de possíveis.

Existe uma discrepância entre o volume de produção de cartas por renomados escritores, pensadores ou artistas e seu devido estudo. Percebe-se o pouco ou recente valor que tem a correspondência de um autor. Não há muito espaço reservado nas livrarias para o gênero. Poucas obras reunindo cartas estão disponíveis, e as pequisas nessa área ainda são pouco numerosas. O gênero teria ficado apartado pela crítica literária, segundo Silviano Santiago, ${ }^{2}$ porque no século XX houve uma separação quase intransponível entre vida e obra nos estudos literários. Não se trata, segundo ele, de pregar um retorno ao biografismo dos historiadores positivistas como Gustave Lanson, que lia os textos sem, na verdade, os ler, ensinando apenas a biografia dos autores. Santiago procura questionar esse enclausuramento defendido pelos formalistas russos, a close reading da nova crítica norteamericana, a leitura estilística dos espanhóis e germânicos, a

\footnotetext{
${ }^{1}$ RÓNAI. Escola de tradutores, p. 84.

${ }^{2}$ SANTIAGO. Org. e notas. In: ANDRADE; ANDRADE. Carlos \& Mário: correspondência completa entre Carlos Drummond de Andrade (inédita) e Mário de Andrade, p. 9-10.
} 
análise estrutural francesa, por exemplo, afirmando que a leitura do gênero epistolar

visa a enriquecer pelo estabelecimento de jogos intertextuais, a compreensão da obra artística (poema, conto, romance...), ajudando a melhor decodificar certos temas que ali estão dramatizados, ou expostos de maneira relativamente hermética $(. ..){ }^{3}$

A análise dessa correspondência em seu conjunto provocou um importante choque na imagem que eu tinha de Baudelaire até então. O poeta maldito, da infância revoltada, com relacionamento conturbado com o padrasto e que não superou a fase edipiana, imagem afirmada de forma contundente por alguns comentaristas, inclusive, a partir de trechos de cartas, embateu-se aos poucos com outro Baudelaire. Ao final, o contato direto com essas epístolas abriu espaço para a dúvida e para o questionamento dessa imagem mistificada, o que instigou minha curiosidade para com as missivas baudelairianas e o que poderiam ainda revelar. $\mathrm{E}$ a importância do estudo destas ganha em intensidade se pensarmos que o mais renomado tradutor dos versos do poeta no Brasil, Ivan Junqueira, reproduz essa imagem questionável. Foi justamente contra seu ensaio "A arte de Baudelaire" que minha leitura da correspondência se chocou. Além disso, este estudo, que precede sua tradução, está presente notadamente no volume único Poesia e prosa, publicado em 1995 pela editora Nova Aguilar, e igualmente pela editora Nova Fronteira. É referência sua tradução de As flores do mal (1985), considerada um best-seller por ter ultrapassado sua $10^{a}$ edição e única de renome realmente acessível

3 SANTIAGO. Org. e notas. In: ANDRADE; ANDRADE. Carlos E Mário: correspondência completa entre Carlos Drummond de Andrade (inédita) e Mário de Andrade, p. 9-10. 
atualmente tanto por leitores comuns quanto para acadêmicos. ${ }^{4}$ Outro tradutor, não menos renomado, José Paulo Paes, afirma: "Depois de perder o pai quando contava apenas 6 anos de idade, Charles Baudelaire (1821-1867) jamais se conformou com o segundo casamento de sua mãe, que o levou desde cedo a atitudes de rebeldia." No que se refere às pesquisas acadêmicas, depareime com a tese intitulada Edgar Allan Poe e Charles Baudelaire: trajetórias e maturidade estética e poética,${ }^{6}$ que confirma a famosa revolta com o segundo casamento de sua mãe. Portanto, a hipótese aqui avançada é que Ivan Junqueira está inserido em um pensamento que tem origem em outros baudelairianos. De certa forma, uma linhagem francesa de pesquisadores (Crépet pai e filho, Pichois, de um lado, e Porché e Sartre, do outro), em graus e formas diversas, pode ter "contaminado" - como em um efeito dominó - essa imagem que se tem de Baudelaire, fortemente irradiada no Brasil por Ivan Junqueira, que, por sua vez, parece ter alimentado o eco de um histórico eco. Encontramos em Sartre, por exemplo, as mesmas afirmações. O discurso do filósofo francês não deixa espaço para dúvidas; não questiona, afirma; enfim, em um estilo impar, constrói uma argumentação de grande poderio que deixa pouco espaço ao questionamento.

Muito se diz a respeito da lenda alimentada por Baudelaire para estabelecer sua reputação. Os artigos dos jornalistas Louis Goudall ou de Édouard Duranty, ambos do jornal Le Figaro, são reveladores desse mal-entedido, da confusão entre o eu poético e o autor como indivíduo real. Os temas de As flores do mal são

\footnotetext{
${ }^{4}$ MEIRELLES. Baudelaire no Brasil: traduções, p. 99. As traduções de Guilherme de Almeida (seleção) e de Haddad estão esgotadas. A da Martin Claret, muito "próxima" da de Haddad, não contém nenhum ensaio sobre o poeta, como era de se esperar.

${ }^{5}$ PAES. Poesia erótica em tradução, p. 192.

${ }^{6}$ PHILIPPOV. Edgar Allan Poe e Charles Baudelaire: trajetórias e maturidade estética e poética.
} 
diretamente associados ao autor indivíduo real: daí decorre a expressão "Prince des Charognes" e a associação da fisionomia do poeta a um lobisomen. Como se Mary Shelley fosse ela mesma monstruosa por ser a autora de Frankenstein. Não obstante, vale questionar quem inicou esse mito. É verrossimilhante a possibilidade de Baudelaire, não havendo como lutar contra a mistificação de sua pessoa e de seus versos, ter alimentado o mito que ia se inscrevendo com as publicações dos poemas, em suma, assim que tomava a pena (la plume). Sua originalidade ou até estranheza e a novidade de sua obra podem ter favorecido esse mito. Muitos não entenderam o valor da imaginação e do sonho na escrita baudelairiana, tampouco a revolução que produzia na literatura francesa. Adentrando essa lenda, vale notar o grau de incompreensão da sociedade na qual se debateu e que ultrapassa o lado barroco de Baudelaire. Assim, na Bélgica, ora é visto como agente da polícia secreta francesa, ora cria ele mesmo o rumor de que é homossexual e, cúmulo do absurdo, que matara seu pai e o comera. E acreditaram nele. ${ }^{7}$ Uma senhora que o encontrara, se surpreendera em não ver no poeta um embriagado e fétido personagem cujo retrato era comentado. ${ }^{8}$ Certo dia em Paris, pintou o cabelo de verde e se apresentou ao escritor Maxime Du Camp, membro da Academia Francesa de Letras e amigo de Flaubert, que preferiu fingir nada ver de estranho para contrariar a provocação. Em seus Souvenirs littéraires, o acadêmico chegou até mesmo a descrever o poeta parisiense como sendo ignorante. ${ }^{9}$ Baudelaire mandou sua candidatura para a Academia postulando a cadeira de um religioso, para a grande surpresa (ou escândalo) de muitos, todavia, respeitava sinceramente a obra de Henri

\footnotetext{
${ }^{7}$ Carta a Madame Paul Meurice, Bruxelas, 3 de janeiro de 1865. In: BAUDELAIRE. Correspondance I, II: 1832-1860/1860-1866, p. 437-438.

${ }^{8}$ Carta a Sainte-Beuve de 24 de janeiro de 1862. In: BAUDELAIRE. Correspondance I, II: 1832-1860/1860-1866, p. 219-221.

${ }^{9}$ DU CAMP. Souvenirs littéraires, p. 65.
} 
Lacordaire. Das Flores do mal, o próprio autor disse, supondo que a obra fosse diabólica: "existe-t-il, pourrait-on dire, quelqu'un de plus catholique que le Diable?" 10 Sua conduta e suas vestimentas originais, seu gosto em provocar a surpresa na estética do putsch, a temática de sua poesia, deviam parecer bastante excêntricas para o homem burguês do século XIX, inclusive, por parte dos autores renomados da época que viam no folhetim uma forma de prosperidade, na literatura, um veio mercantil. Autoridades/ celebridades dignas, homens de mérito no molde da melhor burguesia, Baudelaire os provocara com pequenas frases como: "eu que sou filho de padre." O próprio Delacroix, que o poeta tanto admirou e louvou, jamais retribuiu essas considerações. Tornouse o "Prince des Charognes" ou o "monstrueux excentrique" cuja feiúra era descrita como repulsiva, pela imagem que dilatava na mente dos leitores a partir da obra e dos artigos de jornais. Assim que tomou a pena, como qualquer autor que perde o controle sobre seu texto ao resvalar de suas mãos, teve que lidar com rumores e julgamentos moralizadores que encobriram o valor de sua poesia. A mão suportava uma pena maior e o mal-entendido que foi talvez não tivera outra escolha para se rir das tolices senão alimentar, de forma provocativa, as fontes do mal-entendido.

Examinando alguns títulos de estudos sobre a vida de Baudelaire, não há como não se surpreender, tais como: Baudelaire devant la douleur [Baudelaire frente à dor], de Jean Massin (1944) ou La vie douloureuse de Charles Baudelaire [A vida dolorosa de Charles Baudelaire], de François Porché (1927), obra, aliás, que é frequentemente citada. Os títulos em si já levam para uma riscosa direção. Pois, como veremos, o poeta escolheu sua vida. Não foi vítima de uma fatalidade - a não ser para o olhar

\footnotetext{
${ }^{10}$ Carta a Victor de Laprade datada de 23 de dezembro de 1861. In: BAUDELAIRE. Correspondance I, II: 1832-1860/ 1860-1866, p. 197-200. Seria bastante interessante fazer um paralelo aqui com o conto de Machado de Assis, "A igreja do diabo".
} 
místico - que pesou sobre seus ombros mais do que qualquer outro sujeito comum. Lembremos da miséria dos pobres frente ao café no poema "Os olhos dos pobres", do próprio Baudelaire, das condições de trabalho nas minas retratadas em Germinal de Zola: ficção que pinta a dura realidade da época. Ao analisar o triste fim da filha dos Bovary, verdadeira vítima do romance de Flaubert, como aceitar alguma maldição sobre o destino do poeta? Com exceção da perda do pai aos 6 anos de idade, qual vida particularmente dolorosa Baudelaire teve que não tivesse por origem a própria vereda que decidiu tomar? O jovem Charles se aproxima mais da imagem do filho mimado do que do rebelde rejeitado, como assinala aliás Pichois. Alcançando a maioridade, tinha a oportunidade de fazer uma brilhante carreira, segundo os ideais burgueses e as esperanças dos pais, inclusive com o apoio do padrasto, conforme o que relata a mãe do poeta. Talvez seja descabido atribuir-lhe o rótulo de "poeta maldito". O termo acarreta uma conotação religiosa por demais forte. ${ }^{11}$ Mesmo que seja interpretada no sentido do artista condenado pela sociedade, o amálgama parece quase inevitável. Já é hora de questionar essa expressão, pois, até mesmo pela idade em que faleceu, não haveria como afirmar que foi uma morte tão precoce. A "expectativa média de vida aumentou muito ao longo do século XIX. Em 1801, era de 30 anos. Em 1850, é de 38 anos para os homens e de 41 para as mulheres; em 1913, de 48 anos para os homens e de 52 para as mulheres." ${ }^{\prime 2}$ Contando com a disparidade entre a burguesia e o povo, ainda assim, em uma cidade como Bordeaux em 1823, a

\footnotetext{
${ }^{11}$ Conforme definições extraídas do Dicionário eletrônico Houaiss de língua portuguesa versão 1.0.: 1. "que ou aquele que foi objeto de maldição; amaldiçoado, condenado". 4. "Que ou aquele que o destino e a sociedade parecem condenar, cuja produção passa despercebida ou é alvo de escárnio (diz-se de artista, poeta)."

12 PERROT. História da vida privada, 4: da Revolução Francesa à Primeira Guerra, p. 238.
} 
idade média no momento da morte é de 49 anos entre os burgueses. Ora, malgrado Baudelaire tenha levado uma vida desregrada na vida adulta, longe de todos os confortos de um lar acolhedor, fugindo aos credores e sofrendo das consequências da sífilis, faleceu com pouco mais de 46 anos. À guisa de comparação, Flaubert faleceu com 58 anos, Balzac e Verlaine com 51 anos, Mallarmé, 56 anos, Gautier, 61 anos, Eugène Sue, 53 anos, SainteBeuve, 64 anos. As exceções são escritores como Victor Hugo (83 anos), Lamartine (79 anos), Rimbaud (37 anos) e artistas como Nadar (89 anos). Não há como negar que existem poucos elementos para julgar do sofrimento de jovem Charles quando da morte de seu pai. Por outro lado, os males dos quais sofreu em decorrência da doença venérea até a afasia, tendo em vista o pouco avanço da medicina sobre esse mal na época, foi fonte de dores virulentas no final de sua existência. Mesmo assim, tratava-se de um dos males do século, juntamente à tuberculose, tendo por fonte uma conduta de vida que Charles sabia não ser desprovida de riscos. Muito provavelmente, como se observa em uma missiva de 1839, já havia sido aconselhado por um amigo do meio-irmão quando sofrera de uma blenorragia, conforme aponta Pichois. Baudelaire é muito mais o poeta étranger, como em seu poema em prosa, do que amaldiçoado ou mesmo infortunado.

Essas constatações nos levam ao ponto em que se deve retomar e examinar com cautela a correspondência do poeta. Há duas vertentes que precisam ser questionadas: a famosa fissura ("fêlure"), entendida como trauma, depois do segundo casamento com o oficial Aupick que provocara a revolta do jovem Charles, e a relação passional, segundo Porché, incestuosa, conforme Sartre e Junqueira, entre a mãe e o poeta em devir. Em que medida essas duas questões não corroboram o mito? A revolta ou conflito que provocara a fratura entre Charles e sua família já ocorrera na infância ou se manifestara aos poucos, na mesma medida que aflorava sua individualidade de artista, irrompendo na aurora de seus 21 anos? O complexo de Édipo e a relação incestuosa podem ser afirmados com tanta veemência por Sartre e Junqueira? 
Para averiguar essas questões, devemos nos aprofundar no período da infância e da juventude nas suas relações com a família. Relembremos aqui a importância do ensaio de Junqueira em sua repercussão, já que sua tradução é referência no Brasil, tanto para acadêmicos como para os demais leitores. Reside aqui, entre a aura do renomado tradutor e seu ensaio, a possibilidade da aceitação de suas afirmações, visto que se tem pouco contato com a correspondência de Baudelaire.

Abordemos então as questões propostas pelos propagadores da ideia de "fissura" que se deu na infância e a de relação incestuosa. Essa "fissura" foi afirmada por Jules Buisson, camarada de Baudelaire do tempo da pensão Bailly. Buisson afirma durante uma entrevista com Eugène Crépet realizada em 1886 que: "Baudelaire était une âme très délicate, très fine, originale et tendre mais féminine et faible qui s'était fêlée au premier choc avec la vie." 13 Três gerações de pesquisadores, Eugène e Jacques Crépet (pai e filho) e Claude Pichois, assim como Sartre, reproduziram essa declaração. Todavia, Pichois dá uma conotação positiva à fissura vendo nela o motivo pelo qual os sonhos burgueses ruíram na mente do poeta. Por sua vez, Sartre exacerba sua importância como trauma sofrido por Baudelaire, fonte de sua revolta e de seu ódio contra o padrasto. Um comentário aparentemente anódino de Pichois, na impressionante biografia do poeta, alerta o pesquisador para as concepções do feminino e do masculino. $\mathrm{O}$ renomado baudelairiano afirma que sua atitude admirativa para com as amazonas e a guerreira supõe um gosto profundo pelas mulheres marcadas pelo signo masculino. As declarações, de Buisson a Crépet, não se sustentam por muito tempo perante uma leitura pautada nos estudos de gênero. Pode-se perceber até certo preconceito na oposição estabelecida pela conjunção "mas":

${ }^{13}$ PICHOIS; ZIEGLER. Baudelaire, p. 142. "Baudelaire tinha uma alma muito delicada, muito fina, original e terna, mas feminina e fraca que se fissurara ao primeiro choque com a vida." (tradução nossa) 
tinha uma alma muito delicada, muito fina, original e terna, mas feminina e fraca. $\mathrm{O}$ valor negativo imprimido à feminilidade não pode ser aceito, principalmente ao lembrar que antes mesmo de qualquer tipo de essência do feminino, o gênero se estabelece muito fortemente pelos discursos que irradiam qualquer sujeito. Essas afirmações lembram a falida expressão "sexo frágil". De formas bem distintas, Pichois e Sartre propagam essa ideia de fissura em Baudelaire, sendo que o primeiro não sustenta a famosa revolta do jovem Charles e o segundo reproduz essa ruptura com Aupick após as segundas núpcias da mãe, provendo um forte argumento para o complexo de Édipo.

É preciso agora abordar as afirmações do filósofo francês. Tratar-se-ia da proposta de uma psicanálise existencial. Sartre escreve essa obra no momento em que tenta por em prática a teoria mencionada.

Sartre propõe-se a investigar a biografia de Baudelaire na busca de desvendar o projeto original do poeta, pois é exatamente a partir da iluminação do projeto original de um indivíduo que, segundo Sartre, a psicanálise poderia alcançar os móbeis e os motivos que fundamentam as escolhas humanas. A questão então seria a seguinte: de que forma a investigação de uma biografia nos daria os elementos necessários ao desvelamento desse projeto? Em primeiro lugar, a resposta vem sustentada pela premissa colocada por Freud e assimilada pelo nosso filósofo, segundo a qual, qualquer ato ou comportamento humano é sempre simbólico, ou seja, é sempre a manifestação empírica de uma estrutura mais profunda que, para Freud, estaria localizada numa instância inconsciente do aparelho psíquico, mas que, de acordo com Sartre, relacionava-se à escolha singular que cada indivíduo faz de si mesmo e que se manifesta em cada uma de suas escolhas empíricas realizadas na imediaticidade de suas vivências cotidianas. Dessa 
forma, ele conclui que se o homem é de fato um todo, esse todo deve expressar-se inteiramente em qualquer de suas condutas, por mais insignificantes que elas possam parecer. ${ }^{14}$

Se esse todo se expressa pelas condutas, mesmo insignificantes, a dúvida que surge é: qual conduta eleger como digna de interesse ou como símbolo de um comportamento humano? Pois esse projeto sartriano parece escolher metodicamente alguns trechos epistolares e da obra poética em detrimento de muitos outros que poderiam apontar em direção oposta.

Lorsque son père mourut, Baudelaire avait six ans, il vivait dans l'adoration de sa mère; fasciné, entouré d'égards et de soins, il ne savait pas encore qu'il existât comme une personne, mais il se sentait uni au corps et au cour de sa mère par une sorte de participation primitive et mystique; il se perdait dans la douce tiédeur de leur amour réciproque; il n’y avait là qu'un foyer, qu'une famille, qu'un couple incestueux. ${ }^{15}$

Como empregar, com tanta segurança, expressões como "unido ao corpo", "participação primitiva e mística" e "casal incestuoso", apenas com algumas frases ou máximas tiradas da correspondência e de $\mathrm{Meu}$ coração $n u$, frases estas carregadas de ambiguidade? Sartre prossegue:

\footnotetext{
${ }^{14}$ BOËCHAT. O encontro de Jean-Paul Sartre e Charles Baudelaire.

${ }^{15}$ SARTRE. Baudelaire, p. 18. "Quando seu pai morreu, Baudelaire tinha seis anos, vivia na adoração de sua mãe; fascinado, envolto em atenções e cuidados, não sabia ainda que existia enquanto pessoa, mas sentia-se unido ao corpo e ao coração de sua mãe por uma sorte de participação primitiva e mística; perdiase na suave tepidez de seu amor recíproco; havia apenas um lar, uma família, um casal incestuoso." (tradução nossa)
} 
En novembre 1828 cette femme tant aimée se remarie à un soldat; Baudelaire est mis en pension. De cette époque date sa fameuse "fêlure". Crépet cite à ce sujet une note significative de Buisson: "Baudelaire était une âme très délicate, très fine, originale et tendre, qui s'était fêlée au premier choc de la vie." Il y avait, dans son existence, un évènement qu'il n'avait pu supporter : le second mariage de sa mère. ${ }^{16}$

Constatamos nessa citação a reprodução da frase de Jules Buisson. Todavia, é preciso lembrar que a mãe de Charles respeita as regras de boa conduta da época no que tange à duração do luto. Em Paris, o decoro exige permanecer de luto durante exatamente um ano e seis semanas, para dois anos no interior. Ora, o pai de Baudelaire faleceu no dia 10 de fevereiro de 1827. Charles tinha quase 7 anos de idade (6 anos e 10 meses) e o segundo casamento ocorreu no dia 8 de novembro de 1828 . $O$ coronel Aupick, segundo os registros, iniciou os trâmites legais em 17 de outubro de 1828. É importante ressaltar também que Charles foi acompanhado pela mãe na pensão Delorme, na cidade de Lyon, para estudar no Collège Royal em janeiro de 1832 e tornase interno desse colégio em outubro do mesmo ano. O intervalo entre o casamento dos Aupick, fonte de tão dolorosa e perene revolta conforme a tradição, e a ida para Lyon para o internato, foi de pouco mais de três anos. Todavia, se observarmos as palavras de Sartre, temos a impressão de uma ruptura imediata no relacionamento mãe-filho provocada pelo matrimônio: "Em novembro de 1828 esta mulher tão amada casa-se novamente com um soldado; Baudelaire é posto em uma pensão. Desta época

\footnotetext{
${ }^{16}$ SARTRE. Baudelaire, p. 18-19. "Em novembro de 1828 esta mulher tão amada casa novamente com um soldado; Baudelaire é posto em uma pensão. Desta época data sua famosa 'fissura'. Crépet cita a respeito uma nota significativa de Buisson: 'Baudelaire era uma alma muito delicada, muito fina, original e tenra, que tinha se fissurado no primeiro choque da vida.' Havia, em sua existência, um evento que não pudera suportar: o segundo casamento de sua mãe." (tradução nossa)
} 
data sua famosa fissura." Vejamos qual é a visão que o principal tradutor das Flores do mal tem do autor traduzido.

A problemática espiritual de Baudelaire deita suas mais fundas raízes no substrato de um conflito familiar que remonta à primeira infância do poeta. Contribuem de forma decisiva para isso os dois casamentos - entre ambos não transcorrem sequer dois anos - de sua jovem mãe, que desposou dois homens mais velhos do que ela: ao contrair as primeiras núpcias, Caroline Archimbaut-Dufäys tinha 26 anos e Joseph-François Baudelaire - o pai de Baudelaire - nada menos que 60 , enquanto o padrasto do poeta, o general Jacques Aupick, contava 39 quando, em novembro de 1828, resgatou Caroline de sua curta viuvez. Baudelaire, então com 7 anos, jamais absorveu esse golpe, tanto assim que, pouco depois, como nos informa François Porché, escreveria: "Quando se tem um filho como eu, não se casa outra vez." Mais espantoso ainda é o que se lê em carta que o poeta enviou à mãe a 6 de maio de 1861 (37 anos depois!) e na qual escreve: "Há em minha infância uma época de amor apaixonado por ti; escuta e lê se (sic) receio. Jamais falei tanto disso a ti. Lembro-me de um passeio de fiacre; saías de uma casa de saúde em que estavas exilada, e me mostraste, para pensar que pensaste em teu filho, desenhos à caneta que fizeste para mim. Julgas que tenho uma memória terrível? Mais tarde, a praça de Saint-André-des-Arts e Neuilly. Longas caminhadas, ternuras sem fim!"

Ocioso acrescentar o que quer que seja. O texto fala por si. Estivesse vivo em fins do século XIX, Baudelaire teria sido um dos mais paradigmáticos pacientes de Freud, a própria encarnação do complexo de Édipo. ${ }^{17}$

${ }^{17}$ JUNQUEIRA. A arte de Baudelaire, p. 61-61. 
Primeiro, os trechos citados são ambíguos e insuficientes, quando não contraditórios, ${ }^{18}$ o que nos impulsiona a examinar com cuidado toda a correspondência de Baudelaire aproximadamente 1.500 cartas, bilhetes, contratos e notas promissórias - de sua infância (1832) até 1866. Segundo, seria preciso circunscrever uma definição ou, ao menos, aprofundar o conceito de complexo de castração, para depois poder afirmar com tanta segurança tal diagnóstico. Além disso, antes mesmo da análise da correspondência, um indício aponta para a ponderação nas afirmações que faz Marcel A. Ruff em seu estudo sobre Baudelaire. De fato, não se trata de um ataque à psicanálise em si, mas da hipótese de um emprego abusivo e talvez superficial da psicanálise. Se o Édipo é, como afirma Juan-David Nasio, o mais crucial dos conceitos psicanalíticos, também pode-se constatar que todas as crianças passariam por duas grandes fases nesse processo formador da identidade sexual adulta. A primeira seria a sexualização dos pais decorrente da experiência vivida pela criança de cerca de 4 anos quando absorvida por um desejo sexual incontrolável. Terá de aprender a limitar seu impulso sob o peso dos limites de seu corpo imaturo, de sua consciência nascente e da Lei tácita que lhe ordena que pare de tomar seus pais por objetos sexuais. A segunda fase se estabelece justamente a partir desses limites na dessexualização dos pais. Eis a essência da crise edipiana: toda criança deverá aprender a canalizar um desejo transbordante. Ainda segundo Nasio, a neurose deitaria suas raízes na dificuldade de superar essa crise. ${ }^{19}$

\footnotetext{
${ }^{18}$ Essa carta citada por Junqueira, datada de 6 de maio de 1861 e enviada por Baudelaire à sua mãe, possui elementos contraditórios, já que, ao mesmo tempo em que o poeta revela essa nostalgia de uma época de segurança e paz junto à mãe, que comenta a falta de habilidade do padrastro para com sua educação, declara seu carinho pelo general Aupick e confirma ter sido injusto com ele. São declarações que se embatem umas com as outras e que certamente introduzem nesta missiva certa ambiguidade: Como interpretar essa nostalgia? ${ }^{19}$ Cf. NASIO, Juan-David. Édipo: o complexo do qual nenhuma criança escapa.
} 
Se todos os seres humanos passam pela fase edipiana, como afirmar com tanta certeza, com apenas algumas citações, por vezes ambíguas e que se opõe a muitas outras, o complexo de Édipo em Baudelaire? A postura que empregar-se-á aqui será a da certeza de uma dúvida. Se a dúvida se instala e se nossa intuição bergsoniana se rebela entre estrondos da palavra "impossível", então outros horizontes de investigação se abrem aos pesquisadores. A dúvida deixa espaço para outras possibilidades, permite novas investidas. Uma crítica mais aprofundada da questão psicanalítica exigiria outra pesquisa. O objetivo é, portanto, o de apontar a fragilidade da teoria do complexo de Édipo em Baudelaire, assim como da sua suposta revolta após o segundo casamento. Essas afirmações contundentes exigem mais ainda um questionamento, já que são propagadas pelo principal tradutor das Flores do mal. Marcel Ruff despertara nossa curiosidade. Robert Kopp confirma nosso questionamento ao afirmar:

Or les rapports entre Baudelaire et son beau-père furent, d'abord, assez bons.

Contrairement à la légende, la haine de Charles ne semble point dater du remariage de sa mère. (...) La brouille intervient au lendemain du baccalauréat, lorsque Baudelaire, au lieu de choisir une carrière bourgeoise, veut entrer dans celles des lettres. ${ }^{20}$

Outra interrogação que se coloca é a relevância da insistência na idade dos maridos. Há um equívoco na idade do coronel Aupick, que teria nascido em 1789 (no período conturbado da Revolução), o que explicaria a falta de certidão de nascimento,

${ }^{20}$ KOPP. Baudelaire: le soleil noir de la modernité. "Ora as relações entre Baudelaire e seu padrasto foram, primeiro, assaz boas. Ao contrário da lenda, o ódio de Charles não parece datar do segundo casamento da mãe. (...) O desentendimento intervem nos dias seguintes após o bacharelado, quando Baudelaire, ao invés de escolher uma carreira burguesa, quer ingressar na das letras." (tradução nossa) 
e que tinha assim apenas quatro anos a mais que Caroline Archinbaut Defayis (ou Defaÿs ou ainda Dufays) nascida em Londres em 1793, conforme a cronologia estabelecida por Pichois e Ziegler. No caso do primeiro casamento, trata-se de uma prática muito comum na época. Não podemos esquecer a condição da mulher no século XIX, enclausurada à vida privada, dependendo de um bom casamento para sua sobrevivência. Muitas vezes esmagando os sentimentos e a individualidade, as famílias impunham o matrimônio arranjado que era fonte de especulação, enriquecimento ou preservação financeira e, sobretudo na nobreza, de estratégias diplomáticas, o que dá à instituição uma importância capital. Não significa que tenha sido o caso para os Aupick, já que Marcel A. Ruff afirma ter sido um casamento de amor. A respeito do conflito familiar e da educação do jovem Charles, Ivan Junqueira comenta:

É também perturbador, já aqui em plano muito mais amplo, o que registra o poeta no fragmento $18 \mathrm{de}$ Projéteis: "O gosto precoce pelas mulheres. Confundia o cheiro das peles com o odor da mulher. Lembrome... Enfim, amava minha mãe por sua elegância. Era portanto um dândi precoce." Bastariam esses poucos textos para confirmar à saciedade (sic) o conflito em que mergulhara o pequeno Charles, que pouquíssimo privou (sic) da intimidade do próprio pai (ao morrer Joseph-François, Baudelaire tinha apenas 6 anos), que jamais se entendeu com o irmão mais velho (Alphonse, filho do primeiro casamento de JosephFrançois), que se viu destituído do amor materno após a chegada do general Aupick e que por este foi tratado, não propriamente de forma odiosa ou distante, mas sob as severas imposições do único critério de que dispunha o padrasto para educação de uma criança: o da disciplina militar. ${ }^{21}$

\footnotetext{
${ }^{21}$ JUNQUEIRA. A arte de Baudelaire, p. 62.
} 
Curioso "conflito" que não se entrega em parte alguma na correspondência durante esse período tão crítico: póscasamento na solidão do internato. Surpreendente também a imagem do padrasto, que certamente tinha uma visão rigorosa da educação, mas que parece simplificada, pois o oficial demonstra preocupação e afeto para com Baudelaire, até o famoso corte entre os dois. Certamente a carreira militar não ajudou o general a aplicar uma pedagogia menos autoritária, mas devemos levar em conta o contexto peculiar da família burguesa, as expectativas e investimentos feitos na criança do século XIX. Muito mais do que o rigor militar, a autoridade despótica do pai/marido ou dos pais com o apoio das leis do Estado - nos parece mais conforme às imposições feitas na educação de um jovem burguês durante sua escolaridade. $O$ filho podia ser facilmente preso por um problema de conduta e a filha ser internada a pedido da família conforme a lei de 1838. Os casos famosos de Adèle Hugo e Camille Claudel são exemplos simbólicos das práticas da época. ${ }^{22}$

22 PERROT. História da vida privada, 4: da Revolução Francesa à Primeira Guerra, p. 109 e 263-264. O pai pode mandar prender os filhos e recorrer às prisões do Estado, como se fazia no sistema das ordens régias, a título de "correção paterna", o qual mantém uma polícia de família em que o poder público age por delegação. Todavia, os artigos 375-382 do Código Civil (Livro I, título IX) definem as condições para isso. "O pai que [tem] motivos de descontentamento muito graves sobre a conduta de um filho" pode apelar ao tribunal do arrondissement; até os dezesseis anos, a detenção não pode se estender para além de um mês, e dos dezesseis anos até a maioridade pode chegar a seis meses. Os procedimentos - e fianças - são bastante simples: nenhum pleito por escrito, nenhuma formalidade judicial além do próprio mandado de prisão, no qual não constam os motivos. Se o filho, depois de libertado, "recai em novos desvios", pode-se solicitar nova detenção. (...) Em todo caso, mesmo que a polícia, por meio do internamento normal, continue a usar o asilo como depósito para os perturbadores da ordem pública, tal instituição passa a se alimentar cada vez mais do drama privado e do conflito familiar, que têm no médico seu juiz e árbitro. 
Para finalizar esta reflexão, apontarei um trecho de uma carta do jovem Charles para seu padrastro. Esse excerto revela o tratamento entre os dois durante toda a infância e juventude do poeta até sua decisão de tomar o rumo das letras: verdadeiro motivo dos problemas familiares. Charles escreve a Aupick para anunciar uma boa notícia e, ao mesmo tempo, para desejar-lhe parabéns "de filho para pai", como ele mesmo escreve, por ter sido nomeado general de brigada. Na mesma, comenta que seu resultado no exame foi medíocre, tendo tido mais sucesso nas disciplinas de latim e grego, o que lhe permitiu obter a nota suficiente ao final. Essa missiva do dia 13 de agosto de 1839 é simbólica no sentido em que aponta para outro Baudelaire, um Baudelaire que se revela aos poucos em sua correspondência e que se embate às afirmações de Junqueira e Sartre.

Je viens de voir une bonne nouvelle et j'en ai une bonne à t'annoncer. J'ai lu ce matin ta nomination dans Le Moniteur, ${ }^{23}$ et je suis bachelier ${ }^{24}$ depuis hier soir à 4 heures. Mon examen a été assez médiocre, excepté le latin et le grec - fort bien - c'est ce qui m'a sauvé.

Je suis bien heureux de ta nomination - de fils à père, ce ne sont pas des félicitations banales comme toutes celles que tu recevras. Moi je suis heureux, parce que je t'ai vu assez souvent pour savoir combien cela t'était dû; j'ai l'air de faire l'homme, et de te féliciter comme si j'étais ton égal ou ton supérieur. - Ainsi pour te dire simplement, sache que je suis bien content. ${ }^{25}$

\footnotetext{
${ }^{23}$ Aupick acaba de ser nomeado marechal de campo (= general de brigada). $\mathrm{O}$ decreto é de 12 de agosto; é publicado no Le Moniteur do dia 13. (N. do T.)

${ }^{24}$ Estudante detentor do diploma de baccalauréat. (N. do T.)

${ }^{25}$ BAUDELAIRE. Correspondance I, II: 1832-1860/1860-1866, p. 77. "Acabo de ver uma boa notícia e tenho uma boa para lhe anunciar. Li esta manhã sua nomeação no Le Moniteur, e sou bachelierdesde ontem à noite às 4 horas. Meu
} 
A tradução das epístolas baudelairianas nos possibilita perceber que Ivan Junqueira seguiu o mesmo raciocínio que Sartre, formando uma sorte de eco a uma forte linha de pensamento francesa. Após a leitura das cartas, mesmo restrita ao primeiro volume que abrange o período de 1832 a 1860 , o questionamento surge ante os olhos e não há mais como aceitar de antemão suas afirmações categóricas na questão da origem do conflito familiar. A correspondência fala com uma voz outra e seria inaceitável pensar que o jovem Charles seja desonesto em todas as suas vozes, dos 11 anos de idade até os anos que antecedem sua maioridade, momento em que ocorre o desentendimento com seu padrasto. A difícil classificação do gênero e todo o cuidado com o qual deve ser abordada a oscilação do sujeito entre pessoa que se revela (para/contra si e para/contra os outros) e persona que se camufla, não justifica uma condenação total do que afirma seu autor. Seria o equivalente a invalidar qualquer argumentação, inclusive a do tradutor brasileiro.

Ao tentar desconstruir esse mito, espera-se ter conseguido instalar a dúvida no leitor/pesquisador, desequilibrando essa imagem do poeta, para que outras investigações sejam possíveis, notadamente pela leitura das epístolas.

exame foi assaz medíocre, exceto o latim e o grego - muito bem - foi o que me salvou." "Estou bem feliz por sua nomeação - de filho para pai, não são felicitações banais como todas aquelas que receberá. Eu estou feliz, porque o vi assaz frequentemente para saber o quanto isso lhe é devido; pareço fazer o homem, e felicitá-lo como se fosse seu igual ou seu superior. - Assim para dizer simplesmente, saiba que estou bem contente." 
Résumé: Cet article a l'intention de présenter de nouvelles perspectives sur le poète français Charles Baudelaire qui sont le résultat de la traduction de certaines de ses lettres. Il s'agit de débattre les valeurs qu'une telle traduction peut apporter au renouvellement de l'image du poète des Les fleurs du mal. Car il existe un mythe Baudelaire, alimenté par lui-même, qui camoufle sa véritable personnalité ou, du moins, simplifie le personnage. Dans ce sens, on interroge dans ce travail l'image du poète maudit, révolté avec le second mariage de la mère e qui n'aurait pas dépassé la phase oedipienne. Voici le profil que le principal traducteur de ses vers au Brésil, Ivan Junqueira, défend sous l'influence de Jean-Paul Sartre. Or, la tradução/ lecture des lettres lance un nouveau regard sur le poète ce qui rend possible de certainement éviter une lecture trop mystifiée/simplifiée de sa personnalité et, peutêtre même, de ses vers.

Mots-clés: Traduction; lettres; Baudelaire; perspectives.

\section{REFERÊNCIAS}

BAUDELAIRE, Charles. Correspondance I, II: 1832-1860/1860-1866. Paris: Gallimard, 1973.

BOËCHAT, Neide C. O encontro de Jean-Paul Sartre e Charles Baudelaire. In: ABRALIC (13 a 17 de julho de 2008) - USP - São Paulo.

DU CAMP, Maxime. Souvenirs littéraires. Tome II: 1850-1880. Paris: L'Harmattan, 1993.

JUNQUEIRA, Ivan. A arte de Baudelaire. In: BARROSO, Ivo (Org.). Charles Baudelaire. Poesia e prosa. Volume único. Rio de Janeiro: Nova Aguilar, 1995.

KOPP, Robert. Baudelaire: le soleil noir de la modernité. Paris: Gallimard, 2004.

MEIRELLES, Ricardo. Baudelaire no Brasil: traduções. In: GUERINI, Andréia; TORRES, Marie-Hélène C.; COSTA, Walter Carlos (Org.). Literatura traduzida e literatura nacional. Rio de janeiro: 7 Letras, 2008. 
NASIO, Juan-David. Édipo: o complexo do qual nenhuma criança escapa. Trad. André Telles. Rio de Janeiro: Jorge Zahar Ed., 2007.

PAES, José Paulo. Poesia erótica em tradução. São Paulo: Companhia das Letras, 2006.

PERROT, Michelle (Org.). História da vida privada, 4: da Revolução Francesa à Primeira Guerra. Trad. Denise Bottmann, Bernardo Joffily. São Paulo: Companhia das Letras, 2009.

PHILIPPOV, Renata. Edgar Allan Poe e Charles Baudelaire: trajetorias e maturidade. estética e poética. Tese (Doutorado), USP, São Paulo, 2004.

PICHOIS, Claude; ZIEGLER, Jean. Baudelaire. Paris: Julliard, 1987.

POMMIER, Jean. Dans les chemins de Baudelaire. Paris: José Corti, 1945.p. 318.

RÓNAI, Paulo. Escola de tradutores. Rio de Janeiro: Nova Fronteira; INL, 1987.

RUFF, Marcel A. Baudelaire. Paris: Hatier, 1957.

SANTIAGO, Silviano. Org. e notas de CDA e Silviano Santiago. In: ANDRADE, Carlos Drummond de; ANDRADE, Mário de. Carlos E Mário: correspondência completa entre Carlos Drummond de Andrade (inédita) e Mário de Andrade. Rio de Janeiro: Bem-Te-Vi, 2002.

SARTRE, Jean-Paul. Baudelaire. Paris: Gallimard, 2000. 